\title{
Epithelial cyst in the anterior chamber after penetrating keratoplasty: a rare complication
}

\author{
CHARLES CLAOUÉ, STASIA LEWKOWICZ-MOSS, AND DAVID EASTY \\ From the University of Bristol Department of Ophthalmology, Bristol Eye Hospital, Lower Maudlin Street, \\ Bristol BSI $2 L X$
}

SUMmARY We report the case of a 25 -year-old man who had a penetrating keratoplasty for keratoconus. A year and a half after surgery a cyst was noted in the anterior chamber, which was observed to enlarge over six months. Because of anxiety about endothelial touch, it was removed surgically. Histologically the cyst was composed of stratified, non-keratinised squamous epithelium attached to loose fibrovascular tissue including islands of melanin-containing epithelial cells. This was interpreted as an epithelial implantation cyst of the anterior chamber of corneal origin attached to iris tissue.

Penetrating keratoplasty is widely used in modern ophthalmic surgery for the visual rehabilitation of patients with corneal scarring or optical aberrations untreatable by other means. Unfortunately the aim of restoring long-term useful vision is not always attained. This may be because of graft rejection, recurrence of disease, optical problems, or complications of surgery.

Surgical complications are relatively rare. We report here a case of anterior chamber epithelial cyst formation after penetrating keratoplasty. Although previously described after cataract surgery, so far as we are aware this is the first reported case occurring after penetrating keratoplasty. Moreover, as the specimen was immediately fixed for electron microscopy, some interesting ultrastructural features are described.

\section{Case report}

A 21-year-old male unemployed motor mechanic was first seen in September 1981 having been referred for assessment following an acute corneal hydrops. He had a past medical history of asthma and eczema.

Examination revealed best visual acuities of $6 / 36-1$ in the right eye and 6/60 in the left eye. The right cornea showed a resolving hydrops, and the left swelling with folds in Descemet's membrane and a Fleischer ring. The eyes were normotensive and comfortable. Skin tests revealed marked hyperCorrespondence to Dr C M P Claoué, Department of Ophthalmology, St Thomas's Hospital, London SE1 7EH. sensitivity to feathers, dog, timothy grass, fescue, tree pollen, wheat grain, and meadow grass. Serum IgE levels were 800 units $/ \mathrm{ml}$ on a first sample, and $1000 \mathrm{units} / \mathrm{ml}$ on a retest.

A right penetrating keratoplasty with unmatched female donor material was performed. The operation went normally, and the patient recovered well, achieving a right visual acuity of $6 / 18$ uncorrected and $6 / 6$ with a contact lens.

Eight months after surgery he sustained a rejection episode with stromal oedema of the whole of the donor tissue and an endothelial rejection line. This required inpatient treatment with hourly $0.1 \%$ dexamethasone drops. After this his cornea improved but with some persisting stromal thickening in the lower third of the donor button. The best right visual acuity was $6 / 9$.

Twenty-one months after keratoplasty a cyst was first noted on the anterior surface of the iris in its midperiphery, in the inferotemporal quadrant of the right eye (Fig. 1). Over the next six months this was observed to enlarge until it threatened to touch the endothelium and to cross the visual axis. The cyst was approximately $8 \times 5 \mathrm{~mm}$ (Fig. 2). Visual acuity was reduced to $6 / 18$ and the eye was inflamed, with an intraocular pressure of $35 \mathrm{mmHg}$.

In view of these findings it was decided to remove the cyst surgically. Under general anaesthesia the right eye was opened by an inferotemporal ab externo approach. The cyst was drained, and found to contain a clear yellow fluid. The collapsed cyst was dissected free of the peripheral cornea and removed 


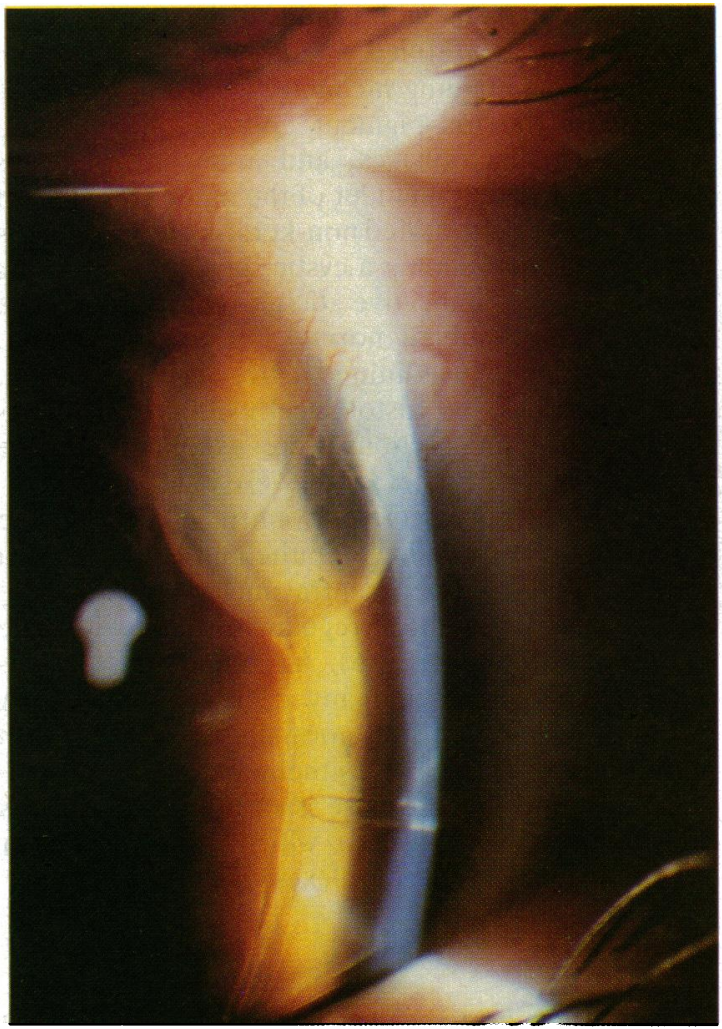

Fig. 1 Epithelial cyst of right eye 21 months after penetrating keratoplasty.

from the eye; the tissue was immediately fixed in glutaraldehyde for electron microscopy. A broad iridectomy with reconstruction of the pupil was

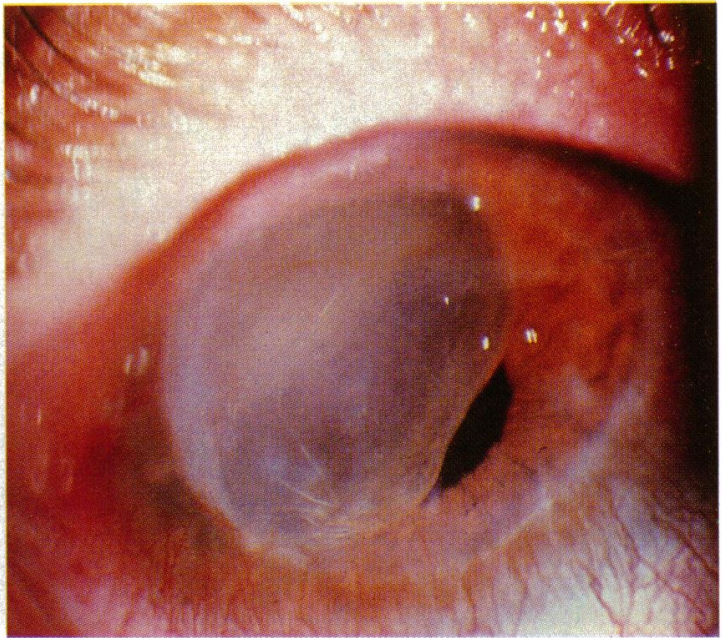

Fig. 2 Epithelial cyst of right eye immediately prior to removal.

performed. The wound was closed with interrupted $10 / 0$ nylon sutures. The patient recovered well from the operation and regained a best right visual acuity of 6/12. A year later the corneal endothelium was examined by the Pocklington specular microscope. The endothelial cells were fairly regular in shape and size, the cell count in the central cornea was $1100 / \mathrm{mm}^{2}$, and there was no evidence of any adherent epithelial cells (Fig. 3).

\section{PATHOLOGICAL EXAMINATION}

Following fixation in $2.5 \%$ glutaraldehyde in $0 \cdot 1$ molar cacodylate buffer with 3 millimolar calcium, $\mathrm{pH} 7 \cdot 2$, the tissue was postfixed in $1 \%$ osmium

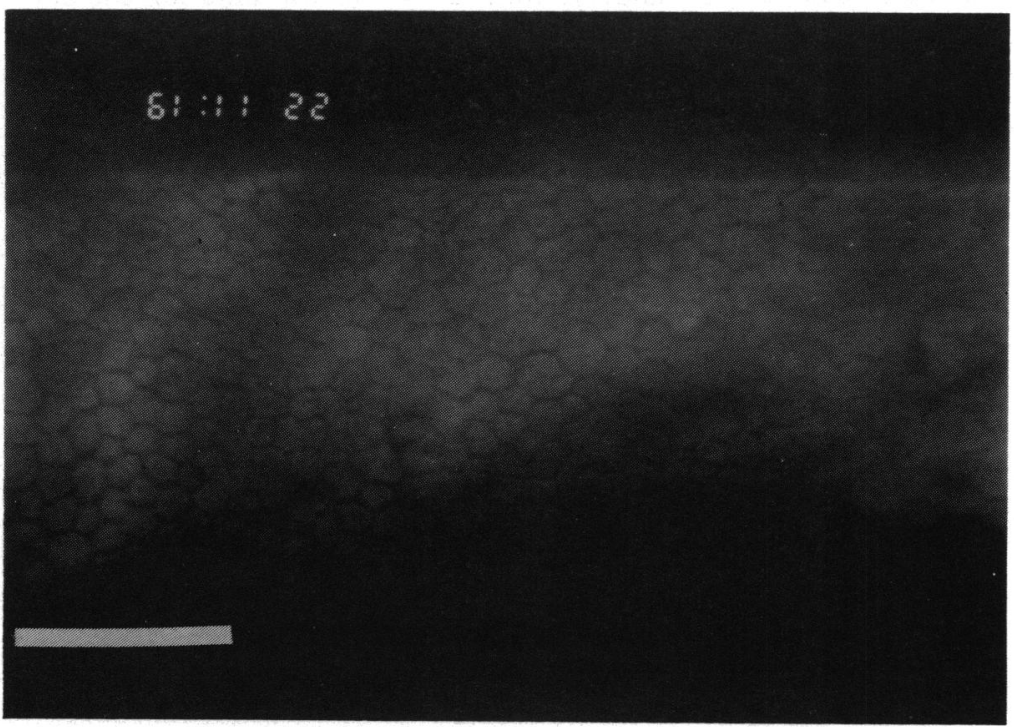

Fig. 3 A specular micrograph of the patient's corneal endothelium one year after removal of the cyst. The cell count is 1100 cells $/ \mathrm{mm}^{2}$. Most cells are hexagonal in shape. but there is some variation in cell size. $\mathrm{Bar}=200 \mathrm{\mu m}$. 


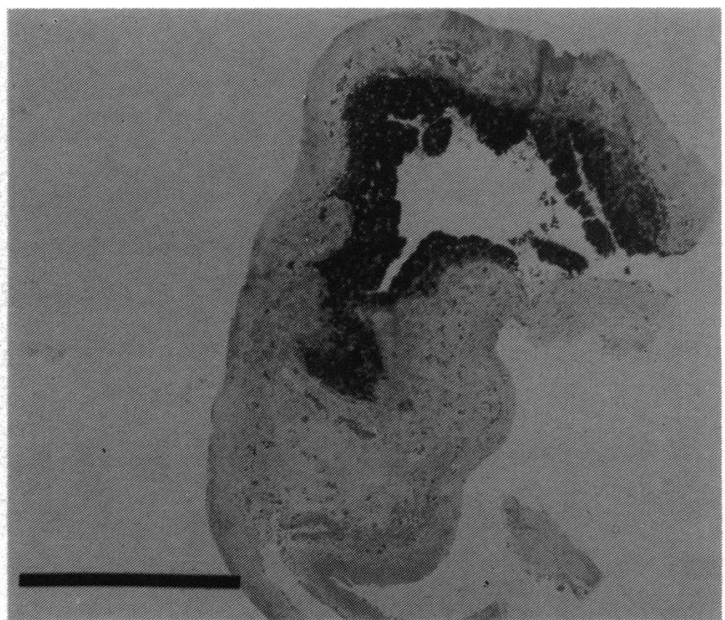

Fig. 4 A light micrograph of a $1 \mu$ m thick plastic section through a portion of the anterior chamber cyst stained with toluidine blue. Pigmented cells resembling iris epithelium are seen towards the top of the picture. Below is an area of fibrovascular tissue. The surface layer is composed of stratified squamous epithelium. Bar $=500 \mathrm{um}$.

tetroxide, dehydrated, and embedded in durcapam epoxy resin (Fluorochtome). Sections $2 \mu \mathrm{m}$ and $5 \mu \mathrm{m}$ thick were cut and stained with haematoxylin/ eosin or toluidine blue for light microscopy. Ultrathin sections were cut, mounted on to copper mesh grids, and stained with uranyl acetate followed by Reynold's lead citrate. The sections were then examined using a Philips 201 transmission electron microscope.

By light microscopy two distinct portions of the cyst were discernible. One was composed of loose fibrovascular tissue with islands of pigmented, nonkeratinising, stratified squamous epithelium apparently containing melanin (Fig. 4). These cells resembled the iris pigment epithelium. Scattered mast cells, macrophages, and a few lymphocytes were noted. The remainder of the tissue consisted of a well organised stratified non-keratinising squamous epithelium surrounding a cystic space, and abutting on to loose connective tissue (Fig. 5A). The epithelium resembled normal corneal epithelium, and in most areas was limited to five or six layers (Fig. 5B). There was no histological evidence of malignancy. The $5 \mu \mathrm{m}$ sections were examined for the presence of Barr bodies; none were noted.

Electron microscopy confirmed that the epithelium resembled the epithelium of the cornea with polygonal cells and central nuclei. However, the nuclei were frequently irregular in shape with pale staining chromatin (Fig. 6). An abundance of tonofilaments was seen in many cells (Figs. 6, 7). A prominent feature, not normally associated with corneal or conjunctival epithelium was the abundance of desmosomes in close association with clusters of tonofilaments (Fig. 7), which at lower power resembled junctional complexes (Fig. 6).

\section{Discussion}

This case appears to be of an iatrogenic epithelial cyst of the anterior chamber following penetrating keratoplasty for corneal hydrops. A rare complication of ocular surgery is the growth of corneal epithelium in the anterior chamber. This may either invade the anterior chamber (usually through a poorly apposed wound) or, if implanted at the time of surgery, form a cyst in the anterior chamber.
Fig. 5A A light micrograph of a $1 \mu \mathrm{m}$ thick plastic section through the remainder of the cyst stained with toluidine blue. The cyst is composed of well organised stratified non-keratinising epithelium with some loose connective tissue. Bar $=200 \mu \mathrm{m}$. 5B A higher power light micrograph demonstrating the five or six layers of epithelial cells. Bar $=20 \mu \mathrm{m}$.

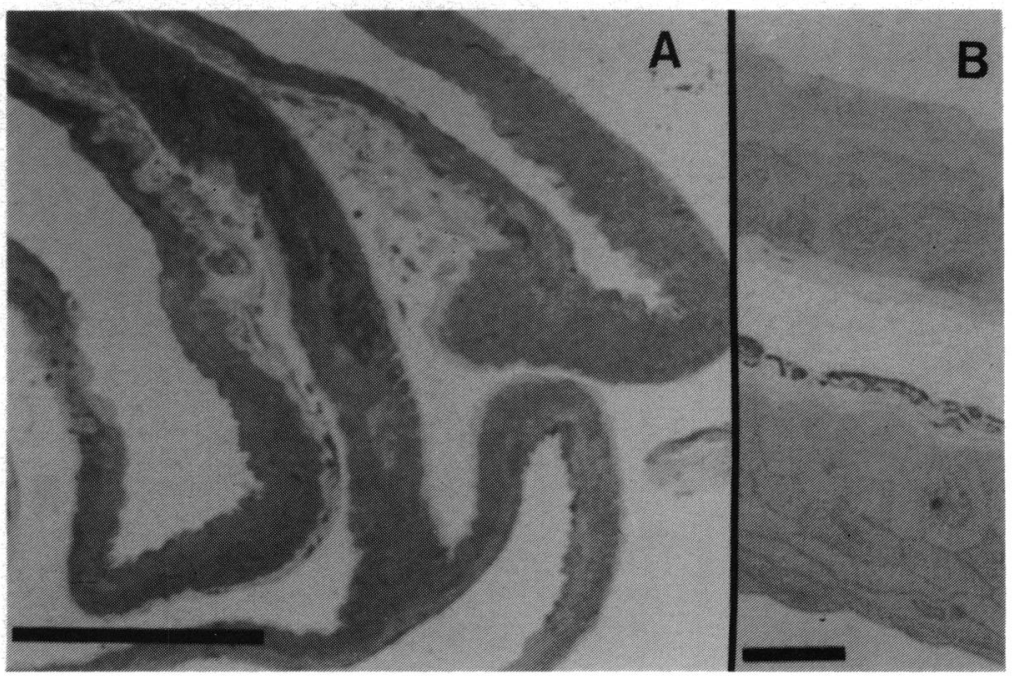




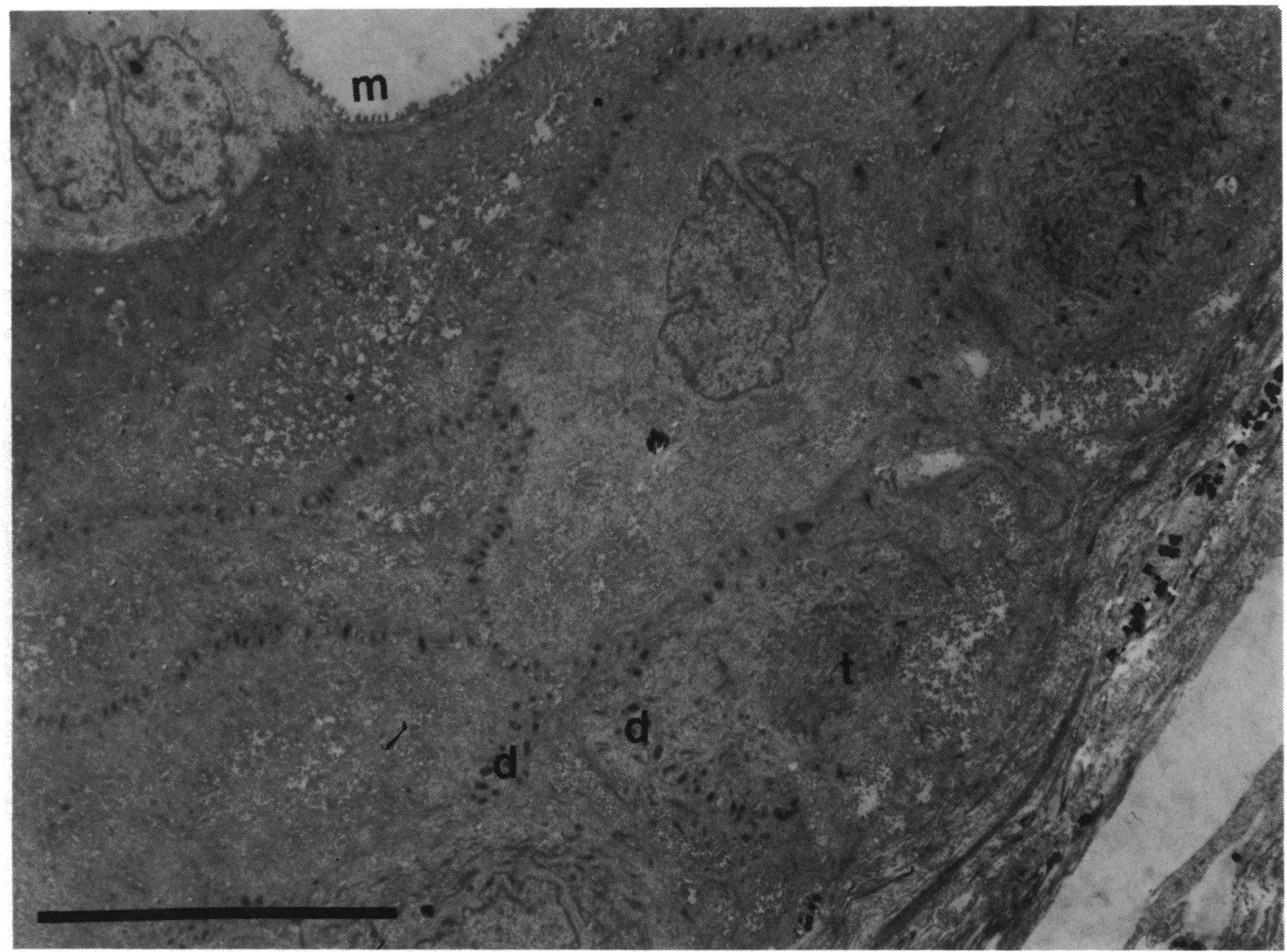

Fig. 6 An electron micrograph of the epithelium of the cyst showing microvilli $(\mathrm{m})$, an abundance of tonofilaments $(\mathrm{t})$. Accumulations of desmosomes (d) can be seen in some cells. Bar $=10 \mu \mathrm{m}$.

Although anterior chamber epithelialisation has been described after penetrating keratoplasty, ${ }^{1-3}$ we are unaware of any previous descriptions of epithelial cysts after this operation. The clinical appearance and behaviour of the lesion in this patient were unlike what has been reported for anterior chamber epithelialisation.

The cyst could be derived from either host or donor epithelium. Our finding that Barr bodies were not seen suggests that the original cells were of host origin, but is not conclusive. If they were, we presume that the original germinal cells may have been carried to the anterior chamber at the time of host cornea trephination. It would seem unlikely that poor wound apposition was the source of epithelial cell invasion as has been suggested for postcataract extraction anterior chamber epithelialisation, ${ }^{+}$since, as Sugar et al. ${ }^{5}$ have pointed out, such a resulting fistula would be readily detectable and would have been repaired without delay. Furthermore, previous reports of anterior chamber epithelialisation have given a mean time from keratoplasty to diagnosis of less than four months' compared with the 21 months which elapsed before any abnormality was detected in the patient reported on here.

The relationship of the cyst to the rejection episode must remain hypothetical. However, a number of interactions are theoretically possible. Microscopic growth of the cyst with early vascularisation might have sensitised the host to the allograft if the epithelium were derived from the donor. The rejection episode itself, with the resultant inflammation and presence of biologically active substances such as lymphkines, might have broken a state of dormancy which had existed since the initial penetrating keratoplasty, and which might in part have been mediated immunologically irrespective of whether the tissue was of host or donor origin. The treatment of the rejection with high doses of steroid might have provided suitable conditions in the anterior chamber for growth of the cyst to begin. Finally, it could be supposed that, had the cyst been of donor origin, the cells would have been killed by immunological mechanisms during the rejection episode.

Histologically the presence of mast cells is of 


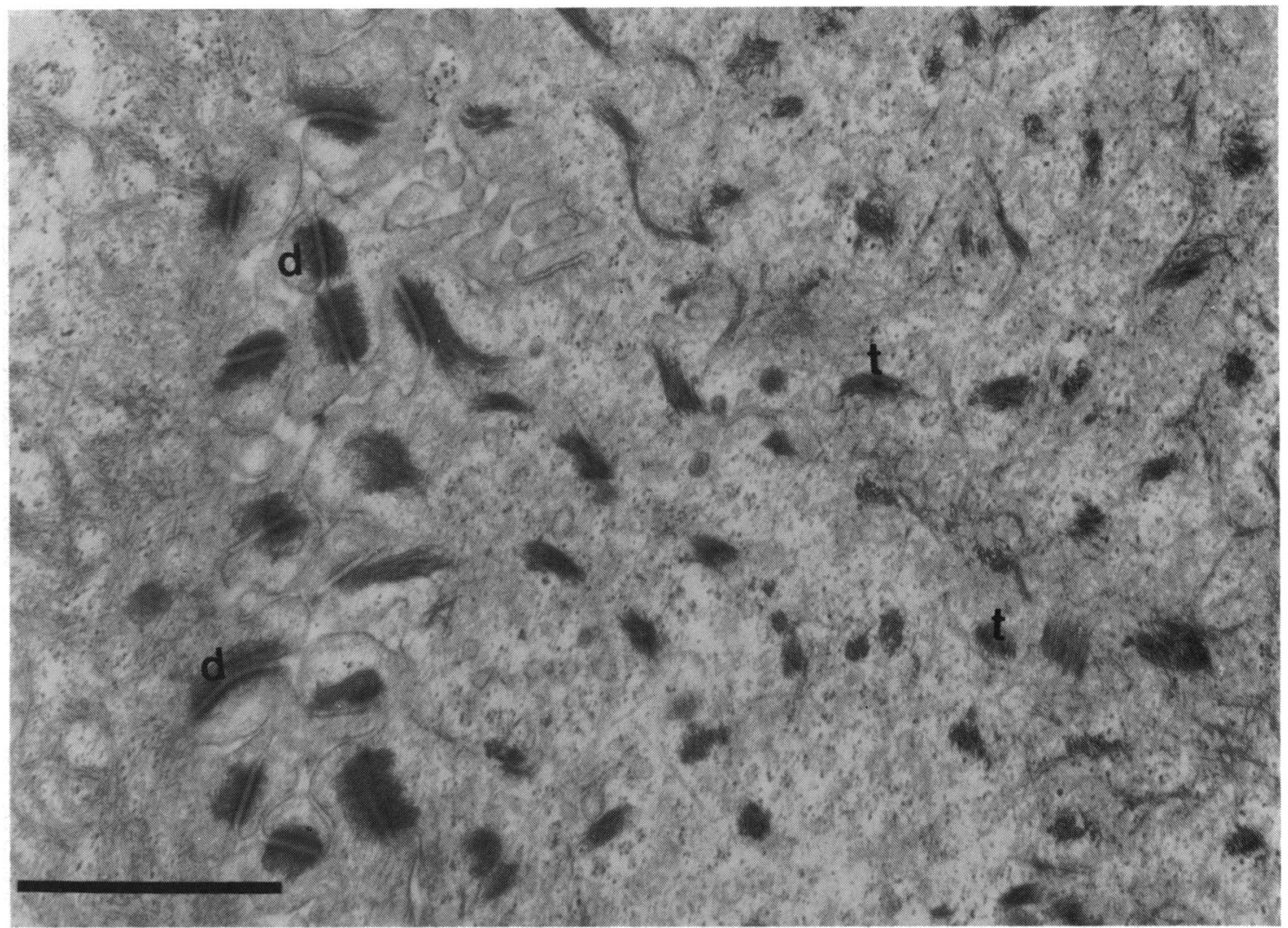

Fig. 7 At higher power, highly convoluted intercellular membranes are seen, with numerous well-formed desmosomes (d). An abundance of short length tonofilaments $(\mathrm{t})$ not associated with a cell membrane are also present. Bar $=1 \mu \mathrm{m}$.

interest. These may have been involved in the elaboration of prostaglandins which in turn were responsible for the elevation of intraocular pressure noted prior to removal of the cyst. Although desmosome complexes are seen in fetal corneal epithelium, they are not typical of the adult tissue. Whether they represent a return to the embryonic state in the environment of the anterior chamber or a response to drug therapy of some unknown variable is not known.

The clinical behaviour of this anterior chamber epithelial cyst mirrors that seen after cataract surgery in that the prognosis for vision appears good. The good prognosis is further enhanced by the endothelial cell count remaining reasonably high despite the rejection episode and the additional surgery. This contrasts markedly with the prognosis for anterior chamber epithelisation.
Dr Claouć is a Wellcome Trust Research Fellow. Dr LewkowiczMoss is funded by the Sir Halley Stewart Trust. We thank Dr T H Moss, for help in interpreting the pathological specimens, and Mr K Gross for doing the specular microscopy.

\section{References}

1 Mazow ML. Stephens RW. An unusual complication after keratoplasty. Surv Ophthalmol 1966; 11: 205-8.

2 Leibowitz HM. Elliott JH, Boruchoff A. Epithelialization of the anterior chamber following penetrating keratoplasty. Arch Ophthalmol 1967: 78: 613-7.

3 Kurz GH. D'Amico RA. Histopathology of corncal graft failures. Am J Ophthalmol 1968: 66: 184-99.

4 Maumenee AE, Paton D, Morse PH. Review of 40 histologically proven cases of epithelial downgrowth following cataract extraction and suggested surgical management. Am J (Ophthalmol 1970): 69: $598-603$

5 Sugar A, Meyer RF. Hood I. Epithelial downgrowth following penetrating keratoplasty in the aphake. Arch Ophthalmol 1977: 95: $464-7$.

Accepted for publication 27 November 1986. 